\title{
The Effect of Combined Training Courses on the Expression of ABCG4 Gene and Interleukin-4 Plasma Level in Middle-Aged Men Undergoing Coronary Artery Bypass Grafting
}

\author{
Fahimeh Yonesi $^{\circledR}$, Amir Rashidlamir $^{2 *}{ }^{\circledR}$, Rambod Khajei $^{(\oplus)}$, Ameneh Barjaste Yazdi $^{\circledR}$ \\ 1Department of Physical Education, Neyshabur Branch, Islamic Azad University, Neyshabur, Iran \\ ${ }^{2}$ Department of Exercise Physiology, Faculty of Sport Sciences, Ferdowsi University of Mashhad, Mashhad, Iran
}

\section{*Correspondence to}

Amir Rashidlamir

Email: rashidlamir@um.ac.ir

Received October 26, 2020

Accepted December 14, 2020

Published online December 30, 2020

\begin{abstract}
Introduction: Atherosclerosis (AS), as a significant cardiovascular disease, is the main factor of death in the world. There has been an association between plasma lipoproteins and AS. Reverse cholesterol transfer (RCT), in which ATP binding cassette (ABC) adenosine triphosphate transporters are major contributors, prevents AS incidence by reducing the accumulation of cholesterol on the walls of blood vessels. Our purpose was to investigate the effect of a combination training session on the gene expression of ABCG4 and plasma level of interleukin-4 (IL-4) in nucleated blood cells of middle-aged men after coronary artery bypass grafting (CABG). Methods: The statistical population consisted of 20 middle-aged men who had previously undergone $\mathrm{CABG}$. After selection, these individuals were randomly divided into two groups of $n=10$; control and combined exercise. At the beginning and end of training sessions, blood samples were obtained to isolate mononuclear cells and extract mRNA. Real-time polymerase chain reaction (PCR) was used for gene expression analysis, and IL-4 was determined by ELISA. SPSS software version 16 was used for data analysis.

Results: The training period remarkably increased ABCG4 expression and IL-4 plasma level compared to the control group.

Conclusion: Combined training, as a part of cardiac rehabilitation in those undergoing CABG may improve the RCT process by affecting the gene expression of ABCG4 and IL-4 production, which are involved in fat burning and metabolism.

Keywords: Combined training, Coronary artery bypass grafting, ABCG4, Interleukin-4
\end{abstract}

Please cite this article as follows: Yonesi $\mathrm{F}$, Rashidlamir A, Khajei R, Barjaste Yazdi A. The Effect of Combined Training Courses on the Expression of ABCG4 Gene and Interleukin-4 Plasma Level in MiddleAged Men Undergoing Coronary Artery Bypass Grafting. Int J Basic Sci Med. 2020;5(4):147154. doi:10.34172/ ijbms.2020.26.

\begin{abstract}
Introduction
Atherosclerosis (AS) is the most common reason of death in industrialized countries, and it has been associated with plasma lipoproteins ${ }^{1}$ because these lipoproteins trigger the deposition of cholesterol on the wall of vesseles. ${ }^{2}$ Phospholipids and cholesterol are key metabolic elements for the body; however, their excessive accumulation of cholesterol may lead to AS. ${ }^{3}$ Reverse cholesterol transfer (RCT) is an anti-atherosclerotic process which is characterized with the accumulation of excess cholesterol from the surrounding tissues, such as arterial wall macrophages, and their return to the liver, along with
\end{abstract}

the formation of HDL. ${ }^{4}$ ATP binding cassette transport $(\mathrm{ABC})$ proteins, which belong to a superfamily of membrane proteins, contribute a prominent role in RCT. ${ }^{5}$ This superfamily includes ABC-A to $\mathrm{G}$ groups ${ }^{6}$; of which the $\mathrm{ABC}-\mathrm{G}$ group has five members (ABC-G1, $-2,-4,-5$, and $-8) .^{7} \mathrm{ABC}$ proteins play an important role in AS because they are essential players in cholesterol metabolism, vascular inflammation, modulation of endothelium function, regulation of blood pressure, and platelet differentiation and accumulation. ${ }^{8}$ The G-type adenosine triphosphate transporter protein is involved in the RCT process in plasma and tissue cholesterol

(c) 2020 The Author(s); Published by Zabol University of Medical Sciences. This is an open-access article distributed under the terms of the Creative Commons Attribution License (http://creativecommons.org/licenses/by/4.0), which permits unrestricted use, distribution, and reproduction in any medium, provided the original work is properly cited. 
metabolic pathways. ${ }^{9}$ ABCG4 is similar in structure and function to ABCG1, which transports cholesterol from macrophages to the liver and regulates cerebral cholesterol metabolism. ${ }^{10}$ During the RCT process, cholesterol is derived out of the intracellular space by some transporter proteins such as ABCA1, ABCG1, and ABCG4, and delivered to the protein which eventually results in HDL formation. ApoA1 is synthesized by the small intestine and liver and enters the bloodstream. ${ }^{11}$

Cytokines have been identified as the molecules produced and released by immune cells, triggering immune responses against pathogens. ${ }^{12}$ There are two main classes of cytokines, including pre- and antiinflammatory; while the first class is involved in the onset and continuance of inflammation, the second class, which includes interleukin-4 (IL-4), is released in response to inflammation, limiting and reversing the inflammatory process. ${ }^{13,14}$ Elevated IL-4 is seen in chronic inflammatory conditions, contributing a main role in the progression of the disease. This cytokine has been shown to be highly elevated in atherosclerotic patients. ${ }^{15}$

The health benefits of exercise, especially its positive effects on cardiovascular function, have long been known; so far, no research has been done on the impacts of combined aerobic and resistance training in cardiovascular patients after coronary artery bypass grafting (CABG) on the expression of ABCG4 gene and IL-4 plasma level.

\section{Materials and Methods \\ Subjects}

The present study was a quasi-experimental research on 60 middle-aged men who had previously undergone CABG surgery in the Javad Al-A'meh Cardiovascular Hospital of Mashhad. As the control group, 20 male eligible volunteers in the age range of 50-60 years were chosen by the convenience sampling method.

\section{Exclusion Criteria}

Patients with ventricular arrhythmias, myocardial infarction over the past four weeks, uncompensated heart failure, and unstable angina pectoris or any other restrictions for exercises were excluded.

\section{Inclusion Criteria}

1. Systolic and diastolic blood pressure of $<160$ and $<100 \mathrm{~mm} \mathrm{Hg}$, respectively.

2. Having cognitive, visual, and auditory health

3. Not using neuroleptics

4. Not using walking aids such as canes and walkers

5. At least 2 months passing since their operation

6. The operating capacity of at least five metabolic equivalent of task (MET), each Met representing 3.5 $\mathrm{mL}$ oxygen consumption per $\mathrm{kg}$ of body weight per minute, which was estimated based on the Bruce's modified test. ${ }^{16}$

\section{Age of 50 to 60 years}

Ten people in each group participated in this study. After screening, the subjects were randomly divided control $(n=10)$ and combined aerobic and resistance training $(\mathrm{n}=10)$ groups.

\section{Exercise instructions}

Tests included Timed Up and Go (TUG) (i.e., unassisted sitting down and standing up in 5 seconds), ${ }^{17}$ Berg Balance Scale (BBS) (3-meter go and back), ${ }^{18}$ and a cardiorespiratory function (6-minute walk) test. $^{19}$ Combined training, which included aerobic and resistance exercises, were performed simultaneously by patients. The subjects performed combined sports activities in the same environment and conditions.

\section{Aerobic Exercise}

Patients in this group, during a 24-session period, exercised three days a week. Each session lasted 90 minutes. The training program included: walking on a treadmill (20 to 30 minutes), pedaling on a stationary bike (10 to 12 minutes), and using a manual ergometer (8 to 10 minutes). All members of this group performed the above exercises during each exercise session. In each session, stretching exercises were used to warm up at the beginning and gradual cooling down was performed at the end of the program. Exercises started with moderate intensity. Thus, in addition to the rate of fatigue and the occurrence of cardiac symptoms, $60 \%$ of patients' heart rates during exercise testing were considered as the target heart rate; according to which the duration and intensity of exercises were adjusted. The intensity and duration of training gradually increased according to the patients' abilities so that during the $7^{\text {th }}$ to $10^{\text {th }}$ sessions, the patients' heart rates reached $80 \% .^{20}$ The details of the aerobic exercise program are listed in Table 1. Based on the patients' initial conditions and the results of the exercise test, the range of beats, the level and intensity of treadmill speed, and the resistance of manual ergometers and stationary bike were recorded for each patient on a sheet. Between the exercises, patients rested for 5 to 10 minutes, depending on their conditions.

\section{Resistance Training}

The sport movements were performed for eight weeks (3 sessions/week) with eight repetitions in initial sessions increasing to 15 repetitions in two sets at late sessions. The movements included Scott with physio ball, ${ }^{21}$ shoulder flexion, ${ }^{22}$ shoulder abduction, ${ }^{23}$ elbow flexion, ${ }^{24}$ thigh flexion, ${ }^{25}$ thigh abduction, ${ }^{26}$ plantar ankle flexion ${ }^{5}$ and Dorsey ankle flexion. ${ }^{6}$ The movements were initially based on the individual's ability, body or limbs weight, and over time, with a weak Traband and finally with a very light weight. ${ }^{27}$ The movements were initially performed with eight repetitions using a weak yellow Traband. Then during each session, two repetitions were 
added to each movement to reach up to 15 repetitions. Then the power of Traband (pink) increased, and again the movements increased initially by eight repetitions and gradually to 15 repetitions in subsequent sessions. Details of the resistance training program are listed in Table 2.

\section{Blood Sampling and Laboratory Measurements}

Forty-eight hours pre-intervention and 48 hours after the final exercise session, all the subjects underwent fasting blood sampling $) 5 \mathrm{~mL}$ (from the brachial vein into test tubes with EDTA anticoagulant. Plasma samples were used to determine IL-4 level using a specific ELISA kit (Cusabio ELISA Kits, China).

The separation of mononuclear cells was done using the Ficoll solution. Mononuclear cells were submerged in liquid nitrogen and crushed completely by a mortar and pestle for mRNA purification. In order to obtain mRNA, the damaged tissue was homogenized in buffer RLT, and then the tissue powder and liquid nitrogen were poured into a 2-mL RNase-free microcentrifuge tube, and the liquid nitrogen was allowed to evaporate while the lymphocytes stayed frozen. Sufficient buffer RLT was added. Lysate was transferred directly to the QIAshredder spin column in a tube and centrifuged at high speed for 2 minutes. After isolating mononuclear cells and extracting mRNA, gene expression analysis was performed using real-time polymerase chain reaction (PCR). ${ }^{28}$ The sequence of the primers has been shown in Table 3 .

In order to reduce some interfering and effective confounder factors in research and to curb the short-term effects of diet on the desired indicators, in this session, the subjects were asked, to refrain from eating fast foods as well as caffeinated beverages for at least 24 hours before exercising and blood sampling.

\section{Statistical Analysis}

The Shapiro-Wilk test was used to determine the normality of data distribution, showing a normal distribution for the variables of age, height, weight, as well as ABCG4 gene expression and IL-4 level in the control and intervention groups at the pre-test and posttest stages. Means and standard deviations were used to describe individuals' characteristics. Paired $t$ test was used to evaluate the differences in the levels of variables before and after training in each group. Independent $t$ test was used to evaluate the differences in the levels of variables before and after training between the two groups. All statistical analyses were performed in SPSS (version

Table 1- Description of Aerobic Exercise Program

\begin{tabular}{|c|c|c|c|c|c|c|c|c|c|c|c|}
\hline Protocol & Device Type & Variables* & Intensity & First & Second & Third & Fourth & Fifth & Sixth & Seventh & Eighth \\
\hline \multirow{6}{*}{$\begin{array}{l}\text { Aerobic } \\
\text { Exercise }\end{array}$} & \multirow{2}{*}{ Navigator } & Intensity (\%) & $60-80$ & 60 & 60 & 65 & 65 & 70 & 75 & 75 & 80 \\
\hline & & Duration (min) & $20-30$ & 20 & 20 & 22 & 24 & 26 & 28 & 30 & 30 \\
\hline & \multirow{2}{*}{$\begin{array}{c}\text { Manual } \\
\text { ergometer }\end{array}$} & Intensity (W) & $30-50$ & 30 & 30 & 35 & 35 & 40 & 45 & 45 & 50 \\
\hline & & Duration (min) & $8-10$ & 8 & 8 & 9 & 9 & 9 & 9 & 10 & 10 \\
\hline & \multirow{2}{*}{$\begin{array}{l}\text { Stationary } \\
\text { bike }\end{array}$} & Intensity (W) & $30-50$ & 30 & 30 & 35 & 35 & 40 & 45 & 45 & 50 \\
\hline & & Duration (min) & $10-12$ & 10 & 10 & 10 & 11 & 11 & 11 & 12 & 12 \\
\hline
\end{tabular}

*The intensity of the sport activity on the treadmill (with variation of $\mathrm{km} / \mathrm{m} / \mathrm{h}$ ) was adjusted to watts according to the heart rate obtained during the exercise and the intensity of the manual ergometer and stationary bike through the resistance applied to the device in watts. Control subjects did not perform any exercise for two months.

Table 2 - Description of resistance training program

\begin{tabular}{|c|c|c|c|c|c|}
\hline Week & The Color of Traband & & Exercises & Number & Repetition \\
\hline First & Yellow & \multirow{4}{*}{ Foot movements } & \multirow{8}{*}{$\begin{array}{l}\text { Scott with a physio ball, } \\
\text { Thigh flexion, } \\
\text { Thigh abduction, } \\
\text { Plantar flexion of the ankle, } \\
\text { Dorsey ankle flexion, } \\
\text { Shoulder flexion, } \\
\text { Shoulder abduction, } \\
\text { Elbow flexion }\end{array}$} & 3 & 8 \\
\hline Second & Yellow & & & 3 & 10 \\
\hline Third & Yellow & & & 3 & 12 \\
\hline Fourth & Yellow & & & 3 & 15 \\
\hline Fifth & Pink & \multirow{4}{*}{ Hand movements } & & 3 & 8 \\
\hline Sixth & Pink & & & 3 & 10 \\
\hline Seventh & Pink & & & 3 & 12 \\
\hline Eights & Pink & & & 3 & 15 \\
\hline
\end{tabular}

Table 3. The Sequences of the Primers Used in the Study

\begin{tabular}{lll}
\hline Gene & Forward Primer & Reverse Primer \\
\hline ABCG4 & 5'-CCGAGACCAGCCGCTTC-'3 & 5'-TCCCAAAGACTGGGCAACTAAG-'3 \\
B-actin & 5'-CCT ATG TTC TCA GCA GCT TC-'3 & 5'-GAA TTT CCT GGC TGT CCC TG-'3 \\
\hline
\end{tabular}


16). A $P$ value of $<0.05$ was considered as a statistically significant observation.

\section{Results}

Baseline anthropometric characteristics of the participants are presented in Table 4 . The mean age of the participants was $58.08 \pm 3.5$ years for the control group and $55.5 \pm 3.6$ years for the experimental group. The mean height was $173.5 \pm 3.69 \mathrm{~cm}$ for the control group and $172.8 \pm 3.5 \mathrm{~cm}$ for the experimental group. The mean weight was 76.16 $\pm 5.23 \mathrm{~kg}$ for the control group and $74.1 \pm 6.4 \mathrm{~kg}$ for the experimental group.

Eight weeks of combined training significantly increased ABCG4 expression $(P=0.001)$ and IL-4 level $(P=0.001)$ compared to the control group. The results are demonstrated in Table 5.

\section{Discussion}

The aim of the present study was to investigate the effects of combined (aerobic and resistance) training sessions on the gene expression of ABCG4 and IL-4 plasma level. The results of this study represented that combined training for eight weeks during cardiac rehabilitation significantly increased the expression of ABCG4 and plasma level of IL-4. In line, a study suggested that exercise can be a promising therapeutic strategy that can increase the functional capacity of patients with heart diseases. ${ }^{29}$
AS is a chronic inflammatory disorder linked with several inflammatory mediators. ${ }^{30}$ Many inflammatory regulators, including macrophage-derived proteins and cytokines, play a key role in the progression and development of the disease. ${ }^{31}$ All four members of the mammalian ABCG proteins (ABCG1, ABCG8, ABCG5, and ABCG4) participate in sterol membrane transportation. ${ }^{32}$ ABCG4, ABCG8, and ABCG5 play essential roles in the RCT process. ${ }^{32}$ The former (i.e., ABCG4) has been reported to be expressed in various human tissues such as the bone marrow, spleen, brain, eyes, and the liver. ${ }^{33}$

The recent studies performed on the effect of endurance exercise on ABCA1 gene expression showed increased expression of this gene in the liver and intestinal tissues. ${ }^{34}$ Also, low-intensity exercise (eight weeks, walking 10,000 steps three times per week) significantly increased ABCA1 and ABCG1 genes' expressions. ${ }^{35}$ In addition, ABCG1 and ABCG4 have been shown to be highly similar in amino acid sequence ${ }^{33}$; therefore, it is possible that the increase in ABCG4 gene expression in the present reflects elevated $\mathrm{ABCA} 1$ and $\mathrm{ABCG} 1$ following exercises. The overexpression of ABCA1, ABCG1, ABCG4, ABCG5 and ABCG8 genes predicts elevation of lipoprotein lipase, hepatic lipase, pre-beta HDL, and lecithin cholesterol acyltransferase, and increased levels of these markers can prevent the development of

Table 4. Demographic and Anthropometric Characteristics of Subjects

\begin{tabular}{|c|c|c|c|c|c|}
\hline \multirow{2}{*}{ Variables } & \multirow{2}{*}{ Groups } & \multicolumn{2}{|c|}{ Pre-test } & \multicolumn{2}{|c|}{ Post-test } \\
\hline & & Mean \pm SD & $\boldsymbol{P}$ & Mean \pm SD & $P$ \\
\hline \multirow{2}{*}{ Age (years) } & Control & $58.08 \pm 3.5$ & 0.364 & - & - \\
\hline & Combined training & $55.5 \pm 3.6$ & 0.237 & - & - \\
\hline \multirow{2}{*}{ Height $(\mathrm{cm})$} & Control & $173.5 \pm 3.69$ & 0.661 & - & - \\
\hline & Combined training & $172.8 \pm 3.5$ & 0.419 & - & - \\
\hline \multirow{2}{*}{ Weight (kg) } & Control & $76.16 \pm 5.23$ & 0.986 & $76.18 \pm 5.23$ & 0.824 \\
\hline & Combined training & $74.1 \pm 6.4$ & 0.769 & $72.9 \pm 6.2$ & 0.635 \\
\hline \multirow{2}{*}{ ABCG4 expression (fold-change) } & Control & $0 \pm 1$ & - & $1.04 \pm 0.47$ & 0.29 \\
\hline & Combined training & $0 \pm 1$ & - & $3.52 \pm 0.68$ & 0.67 \\
\hline \multirow{2}{*}{$\begin{array}{l}\text { IL-4 } \\
(\mathrm{pg} / \mathrm{mL})\end{array}$} & Control & $2.4 \pm 0.75$ & 0.74 & $2.41 \pm 0.8$ & 0.96 \\
\hline & Combined training & $2.45 \pm 0.71$ & 0.75 & $3.6 \pm 0.9$ & 0.32 \\
\hline
\end{tabular}

Table 5 - ABC G4 and IL-4 values separately in different groups

\begin{tabular}{|c|c|c|c|c|c|c|c|}
\hline \multirow{3}{*}{ Variables } & \multirow{3}{*}{ Groups } & \multirow{3}{*}{$\begin{array}{c}\text { Pre-test } \\
\text { Mean } \pm \text { SD }\end{array}$} & \multirow{3}{*}{$\begin{array}{c}\text { Post-test } \\
\text { Mean } \pm \text { SD }\end{array}$} & \multicolumn{4}{|c|}{ Changes } \\
\hline & & & & \multicolumn{2}{|c|}{ Within-Group } & \multicolumn{2}{|c|}{ Between-Group } \\
\hline & & & & $T$ & $P$ & $T$ & $P$ \\
\hline \multirow{2}{*}{$\begin{array}{l}\text { ABCG4 } \\
\text { (fold-change) }\end{array}$} & Combined training & $0 \pm 1$ & $3.52 \pm 0.68$ & 6.3 & $0.001^{*}$ & \multirow{2}{*}{5.021} & \multirow{2}{*}{$0.001^{* *}$} \\
\hline & Control & $0 \pm 1$ & $1.04 \pm 0.47$ & 1.2 & 0.25 & & \\
\hline \multirow{2}{*}{ IL-4 (pg/ mL) } & Combined training & $2.45 \pm 0.71$ & $3.6 \pm 0.9$ & 11.1 & $0.001^{*}$ & \multirow{2}{*}{9.47} & \multirow{2}{*}{$0.001^{*}$} \\
\hline & Control & $2.4 \pm 0.75$ & $2.41 \pm 0.8$ & 0.8 & 0.43 & & \\
\hline
\end{tabular}

Significance of within-group changes using paired samples t-test.

Significance of between-group changes using independent samples t-test. ${ }^{* *}$ 
cardiovascular diseases. ${ }^{36}$ Alterations in cytokines' levels are not only seen in inflammatory diseases, but acute exercise also affects cytokine responses and inflammation in healthy individuals. ${ }^{37}$ Furthermore, the physiological factors induced by exercise such as oxidative stress, heat, acidosis, and stress hormones can affect the release of cytokines. ${ }^{38}$ In addition, cytokine responses may vary in type, duration, recovery period, and extent based on exercise frequency and intensity. ${ }^{37}$

So far, studies have been conducted to investigate the effects of physical activity on gene regulation mechanisms during the RCT process, particularly for the family of $\mathrm{ABC}$ transporters including type $\mathrm{G}$ proteins in animals. ${ }^{39}$

In a study, Zeiaadini Dashtkhaki et al examined the changes of ABCG8 in peripheral blood mononuclear (PBMN) cells following eight weeks of water and dry resistance training in middle-aged women following CABG and showed that both types of exercises induced similar optimal adaptations to ABCG8 gene expression, so this may directly prevent cholesterol deposition on coronary arteries' walls. ${ }^{40}$

In the study of Hosseini et al, it was shown that one session of aerobic and resistance training induced the gene expression of ABCG1 and ABCA1 genes, as well as HDL-C plasma level while decreased plasma LDL-C concentration in athlete women. These findings indicated the positive effects of both training methods in preventing $\mathrm{AS}^{32}$

In another study, it was shown that a change in ABCG4 gene expression after exercise on a treadmill ( 8 weeks $/ 5$ days per week, 1 hour per day, $25 \mathrm{~m} / \mathrm{min}$ ) significantly altered plasma HDL-C level, and a significant correlation was observed between HDL-C fluctuations and ABCG4 gene expression in the small intestine and liver. ${ }^{9}$

Regarding the effects of exercise during cardiac rehabilitation, the study of Moosavi et al, on the effects of 24 sessions of combined training on ABCG1 gene expression in mononuclear cells in middle-aged males undergoing $\mathrm{CABG}$ significantly improved the RCT process, offering beneficial effects for patients with cardiovascular problems. ${ }^{41}$ These results are consistent with the present study, suggesting a positive correlation between the overexpression of ABCG4 transmitter and exercise, improving cardiovascular function.

Ngo Sock et al, in their study investigated the expression of the ABCG5 gene in female rats following moderateintensity aerobic exercise on a treadmill (6 weeks of incremental running at $15 \mathrm{~m} / \mathrm{s}$ and a $0 \%$ incline for 15 minutes ( 2 weeks) to $60 \mathrm{~min} / \mathrm{d}$ with the speed decreasing by 26 meters per minute with a slope of $10 \%$ ( 4 weeks) and five times a week). ${ }^{42}$ They showed a decrease in ABCG5 gene expression that was not consistent with our findings. This may be due to differences in the nature of subjects, given that animals were used in the recent study, as well as the duration and intensity of training.

Also, Suzuki et al in a study in 2014 noted that endurance exercise augmented plasma levels of IL-4 and IL-12 p40, which may suppress the cellular immune response and increase susceptibility to infections. ${ }^{43}$ Schiøtz Thorud et al showed that moderate-intensity exercise positively regulated IL-4, $-5,-6,-10,-2$, tumor necrosis factor alpha (TNF- $\alpha$ ), and transforming growth factor beta in the rat's horseshoe muscle. ${ }^{44}$ In general, IL- 4 may be involved in AS pathogenesis through several pathways, including the modulation of lipoprotein metabolism by regulating lipoxygenase $15,{ }^{45}$ cluster of differentiation 36 (CD36), ${ }^{46}$ and class A sweeper receptor. ${ }^{47}$ By influencing the function of endothelial cells, ${ }^{48}$ as well as macrophages and smooth muscle cells, ${ }^{49}$ IL- 4 can affect the course of inflammatory diseases via reducing the production of inflammatory cytokines. ${ }^{50}$ Rahimi and Shoker Nejad reported a decrease in inflammation with an increase in IL-4 following resistance training. ${ }^{51}$ These results were in agreement with our observations. Another study by Fu et al mentioned that six months of aerobic exercise (four times a week, 60 minutes per session) decreased serum levels of IL-4 and TNF- $a .{ }^{52}$ However Boyd et al, noticed no significant shift in IL-4 and IL-5 serum levels following exercise in humans. ${ }^{53}$ This difference may be related to differences in the type, intensity, and volume of exercises, as well as the nature of subjects.

Significant increase in ABCG4 gene expression and IL-4 plasma level in this study following a combined training session confirmed the antiatherogenic role of IL- 4 through upregulation of ABCG4. Inflammation can downregulate HDL and suppress the RCT process. Structural modifications of HDL during inflammation leads to the production of acute phase HDL, which is relatively rich in apolipoproteins A-IV, serum amyloid A, triglycerides, and fatty acids. This is while anti-inflammatory enzymes (e.g., paraoxanase-1) and cholesterol esters are reduced. Furthermore, myeloperoxidase, an enzyme that converts apolipoprotein A1 and impairs its ability to absorb cholesterol, is increased during inflammation. Finally, inflammation negatively regulates the genes participating in the consumption, secretion, and excretion of cholesterol in the liver (e.g., ABCG5, ABCG8). ${ }^{4}$ So, probably one of the mechanisms by which IL-4 increases ABCG4 is inhibiting the synthesis of inflammatory cytokines such as TNF- $\alpha$ and IL-1 by monocytes. ${ }^{55}$ Therefore, physical activity seems to be a known and practical method to prevent cardiovascular diseases. In fact, moderateintensity physical activity may have anti-inflammatory effects and modulate the production of inflammatory markers. ${ }^{56}$

\section{Conclusion}

In general, it can be said that aerobic and resistance training can improve the RCT process by increasing the gene expression of ABCG4 and plasma level of IL-4 in middle-aged men undergoing CABG, offering many cardiovascular benefits. Thus, despite elucidating the 
effects of exercise on ABCG4 transmitter and IL-4 level, it is necessary to conduct research to examine other key factors in cholesterol uptake from peripheral tissues in high-risk people such as those who suffer from AS or those with a history of open-heart surgery.

\section{Ethical Approval}

This research was approved under the ethics code of IR.IAU.NEYSHABUR.REC. 1399,016 by Islamic Azad University, Neyshabour Branch.

\section{Conflict of Interest Disclosure \\ None.}

\section{Authors' Contributions}

$\mathrm{AR}$ and $\mathrm{RKH}$ conceived and designed this study. FY collected the materials, performed the experiments, analyzed the data and wrote the manuscript. ABY improved the quality of the paper.

\section{Acknowledgments}

AR, FY, RKH and ABY express their gratitude to the Cardiac Rehabilitation Department of Javad Al-A'meh Specialized Cardiovascular Hospital and the patients who helped us in the accurate implementation of the programs with their presence and participation.

\section{Reference}

1. Zhao Y, Dai XY, Zhou Z, Zhao GX, Wang X, Xu MJ. Leucine supplementation via drinking water reduces atherosclerotic lesions in apoE null mice. Acta Pharmacol Sin. 2016;37(2):196-203. doi:10.1038/aps.2015.88

2. Rashidlamir A, Ghanbari-Niaki A, Saadatnia A. The effect of eight weeks of wrestling and wrestling technique based circuit training on lymphocyte ABCA1 gene expression and plasma apolipoprotein A-I. World J Sport Sci. 2011;2(2):144-150.

3. Schmitz G, Kaminski WE, Orsó E. ABC transporters in cellular lipid trafficking. Curr Opin Lipidol. 2000;11(5):493501. doi:10.1097/00041433-200010000-00007

4. Rashidlamir A. Investigation of the effect of aerobic and resistance exercises on peripheral blood mononuclear cells ABCG1 gene expression in female athletes. J Shahid Sadoughi Univ Med Sci. 2012;20(1):1-9. [Persian].

5. Shipp LE, Hamdoun A. ATP-binding cassette (ABC) transporter expression and localization in sea urchin development. Dev Dyn. 2012;241(6):1111-1124. doi:10.1002/dvdy.23786

6. Woodward OM, Köttgen A, Köttgen M. ABCG transporters and disease. FEBS J. 2011;278(18):3215-3225. doi:10.1111/ j.1742-4658.2011.08171.x

7. Wang N, Ranalletta M, Matsuura F, Peng F, Tall AR. LXRinduced redistribution of ABCG1 to plasma membrane in macrophages enhances cholesterol mass efflux to HDL. Arterioscler Thromb Vasc Biol. 2006;26(6):1310-1316. doi:10.1161/01.atv.0000218998.75963.02

8. Davidson AL, Chen J. ATP-binding cassette transporters in bacteria. Annu Rev Biochem. 2004;73:241-268. doi:10.1146/annurev.biochem.73.011303.073626

9. Ghanbari-Niaki A, Rahmati-Ahmadabad S. Effects of a fixed-intensity of endurance training and Pistacia atlantica supplementation on ATP-binding cassette G4 expression. Chin Med. 2013;8(1):23. doi:10.1186/1749-8546-8-23

10. Tarr PT, Tarling EJ, Bojanic DD, Edwards PA, Baldán A. Emerging new paradigms for ABCG transporters. Biochim Biophys Acta. 2009;1791(7):584-593. doi:10.1016/j. bbalip.2009.01.007

11. Ghorani V, Rashidlamir A, Farzanegi P. Effects of 6 Weeks of Aerobic Training and Fenugreek Extract Administration on Plasma Apo AI of Female Patients with Type 2 Diabetes. Ir J Health Phys Act. 2014;5:29-34.

12. Abbas AK, Lichtman AH, Pillai S. Cellular and Molecular Immunology E-Book. Elsevier Health Sciences; 2014.

13. Agha-Alinejad H, Molanouri Shamsi M. Exercise induced release of cytokines from skeletal muscle: emphasis on IL6. Iran J Endocrinol Metab. 2010;12(2):181-190. [Persian].

14. Roselló-Lletí E, Rivera M, Bertomeu V, Cortés R, Jordán A, González-Molina A. [Interleukin-4 and cardiac fibrosis in patients with heart failure]. Rev Esp Cardiol. 2007;60(7):777-780.

15. Sasaguri T, Arima N, Tanimoto A, Shimajiri S, Hamada T, Sasaguri Y. A role for interleukin 4 in production of matrix metalloproteinase 1 by human aortic smooth muscle cells. Atherosclerosis. 1998;138(2):247-253. doi:10.1016/s00219150(97)00296-7

16. Nichols S, O’Doherty A, Carroll S, Ingle L. Influence of appendicular skeletal muscle mass on resting metabolic equivalents in patients with cardiovascular disease: implications for exercise training and prescription. Eur J Prev Cardiol. 2020;27(9):1001-1003. doi:10.1177/2047487319856432

17. Cattaneo D, Regola A, Meotti M. Validity of six balance disorders scales in persons with multiple sclerosis. Disabil Rehabil. 2006;28(12):789-795. doi:10.1080/09638280500404289

18. Fjeldstad-Pardo C, Pardo G, Frederiksen C, Bemben D, Bemben M. Assessment of postural balance in multiple sclerosis. Int J MS Care. 2009;11(1):1-5. doi:10.7224/15372073-11.1.1

19. Maghsoodi N, Khosravi N, Ravasi AA. The effect of a period of selected training (aerobic and resistance) on some cytokines in male and female patients with multiple sclerosis. Journal of Sport Biosciences. 2011;4(10):5-23. [Persian].

20. Knight BL. ATP-binding cassette transporter A1: regulation of cholesterol efflux. Biochem Soc Trans. 2004;32(Pt 1):124-127. doi:10.1042/bst0320124

21. Naghavi M. Transition in health status in the Islamic Republic of Iran. Iran J Epidemiol. 2006;2(1):45-57. [Persian].

22. Moameni H. Impact on Health Behaviors and the Myocardial Infarction Patients Return to Work [dissertation]. Isfahan University of Medical Sciences; 2002. [Persian].

23. Kumada M, Kihara S, Sumitsuji S, et al. Association of hypoadiponectinemia with coronary artery disease in men. Arterioscler Thromb Vasc Biol. 2003;23(1):85-89. doi:10.1161/01.atv.0000048856.22331.50 
24. Shao B, Cavigiolio G, Brot N, Oda MN, Heinecke JW. Methionine oxidation impairs reverse cholesterol transport by apolipoprotein A-I. Proc Natl Acad Sci U S A. 2008;105(34):12224-12229. doi:10.1073/pnas.0802025105

25. Wang HH, Patel SB, Carey MC, Wang DQ. Quantifying anomalous intestinal sterol uptake, lymphatic transport, and biliary secretion in ABCG8-/- mice. Hepatology. 2007;45(4):998-1006. doi:10.1002/hep.21579

26. de la Llera-Moya M, Rothblat GH, Connelly MA, et al. Scavenger receptor BI (SR-BI) mediates free cholesterol flux independently of HDL tethering to the cell surface. J Lipid Res. 1999;40(3):575-580.

27. Pollock ML, Franklin BA, Balady GJ, et al. AHA Science Advisory. Resistance exercise in individuals with and without cardiovascular disease: benefits, rationale, safety, and prescription an advisory from the committee on exercise, rehabilitation, and prevention, council on clinical cardiology, American Heart Association. Circulation. 2000;101(7):828-833. doi:10.1161/01.cir.101.7.828

28. Zare-Kookandeh N, Deldar H, Ghanbari-Niaki A, Ansari Pirsaraei Z, Rahmati-Ahmadabad S, Raoof Z. ABCG1 gene responses to treadmill running with or without Pistachioatlantica in female rats. Iranian Journal of Health and Physical Activity. 2012;3(1):1-7.

29. Ghanbari-Niaki A, Zare-Kookandeh N, Deldar H, ZareKookandeh A, Baghaei-Tehrani R. Visceral fat ABCG1, ABCG5 and visfatin gene expression in response to a treadmill running program with or without a liquid Pistachio-atlantica (Bene) extraction in female rats. Iran J Card Surg. 2013;5(2-3):10.

30. Paoletti R, Gotto AM, Jr., Hajjar DP. Inflammation in atherosclerosis and implications for therapy. Circulation. 2004;109(23 Suppl 1):III20-26. doi:10.1161/01. CIR.0000131514.71167.2e

31. Yin K, Liao DF, Tang CK. ATP-binding membrane cassette transporter A1 (ABCA1): a possible link between inflammation and reverse cholesterol transport. Mol Med. 2010;16(9-10):438-449. doi:10.2119/molmed.2010.00004

32. Hosseini SM, Darrudi S, Talebi K, Rashidlamir A. Effect of resistance and aerobic training on ABCA1, ABCG1 gene expression, HDL-C AND LDL-C lipoprotein levels female athletes. 2017. Available from: https://www.sid.ir/ en/seminar/ViewPaper.aspx?id=46596

33. Bojanic DD, Tarr PT, Gale GD, et al. Differential expression and function of ABCG1 and ABCG4 during development and aging. J Lipid Res. 2010;51(1):169-181. doi:10.1194/ m900250-jlr200

34. Khabazian BM, Ghanbari-Niaki A, SafarzadehGolpordesari A, Ebrahimi M, Rahbarizadeh F, Abednazari $\mathrm{H}$. Endurance training enhances $\mathrm{ABCA} 1$ expression in rat small intestine. Eur J Appl Physiol. 2009;107(3):351-358. doi:10.1007/s00421-009-1133-3

35. Butcher LR, Thomas A, Backx K, Roberts A, Webb $\mathrm{R}$, Morris K. Low-intensity exercise exerts beneficial effects on plasma lipids via PPARgamma. Med Sci Sports Exerc. 2008;40(7):1263-1270. doi:10.1249/ MSS.0b013e31816c091d

36. Shulenin S, Schriml LM, Remaley AT, et al. An ATPbinding cassette gene (ABCG5) from the ABCG (White) gene subfamily maps to human chromosome 2 p21 in the region of the Sitosterolemia locus. Cytogenet Cell Genet. 2001;92(3-4):204-208. doi:10.1159/000056903

37. Calle MC, Fernandez ML. Effects of resistance training on the inflammatory response. Nutr Res Pract. 2010;4(4):259269. doi:10.4162/nrp.2010.4.4.259

38. Brochu M, Malita MF, Messier V, et al. Resistance training does not contribute to improving the metabolic profile after a 6-month weight loss program in overweight and obese postmenopausal women. J Clin Endocrinol Metab. 2009;94(9):3226-3233. doi:10.1210/jc.2008-2706

39. Ghanbari-Niaki A, Ghanbari-Abarghooi, Gholizadeh M. Heart ATP-Binding Cassette Protein A1 and G1, Peroxisome Proliferator-Activated Receptor- $\alpha$ and Liver $\mathrm{X}$ Receptors Genes Expression in Response to Intensive Treadmill Running and Red Crataegus pentaegyna (Sorkh valik) in Male Rats. Zahedan J Res Med Sci. 2015;17(5):1-5. [Persian].

40. Zeiaadini Dashtkhaki L, Rashidlamir A, Naghibi S. Changes of ATP -binding cassette transporter type G8 gene expression subsequent eight weeks of quatic and dryland resistance training in middle-aged women's peripheral blood cells after coronary artery bypass grafting. J Sabzevar Univ Med Sci. 2018;25(4):473-483. [Persian].

41. Moosavi R, Rashidlamir A, Khajei R, Hejazi M. The effect of combined training on ABCG1 gene expression in mononuclear cells after coronary artery bypass surgery in middle aged men. J Neyshabur Univ Med Sci. 2019;7(3):4962. [Persian].

42. Ngo Sock ET, Farahnak Z, Lavoie JM. Exercise training decreases gene expression of endo- and xeno-sensors in rat small intestine. Appl Physiol Nutr Metab. 2014;39(10):10981103. doi:10.1139/apnm-2013-0573

43. Suzuki Y, Suzuki K, Yokoi Y, Miyagawa Y, Metoki T, Nakazawa M. Effects of intravitreal injection of bevacizumab on inflammatory cytokines in the vitreous with proliferative diabetic retinopathy. Retina. 2014;34(1):165-171. doi:10.1097/IAE.0b013e3182979df6

44. Schiøtz Thorud HM, Wisløff U, Lunde PK, Christensen G, Ellingsen $\varnothing$, Sejersted OM. Surgical manipulation, but not moderate exercise, is associated with increased cytokine mRNA expression in the rat soleus muscle. Acta Physiol Scand. 2002;175(3):219-226. doi:10.1046/j.1365201X.2002.00990.x

45. Reardon CA, Blachowicz L, White T, et al. Effect of immune deficiency on lipoproteins and atherosclerosis in male apolipoprotein E-deficient mice. Arterioscler Thromb Vasc Biol. 2001;21(6):1011-1016. doi:10.1161/01.atv.21.6.1011

46. Yesner LM, Huh HY, Pearce SF, Silverstein RL. Regulation of monocyte CD36 and thrombospondin-1 expression by soluble mediators. Arterioscler Thromb Vasc Biol. 1996;16(8):1019-1025. doi:10.1161/01.atv.16.8.1019

47. George J, Shoenfeld Y, Gilburd B, Afek A, Shaish A, Harats D. Requisite role for interleukin-4 in the acceleration of fatty streaks induced by heat shock protein 65 or Mycobacterium tuberculosis. Circ Res. 2000;86(12):12031210. doi:10.1161/01.res.86.12.1203

48. Lee YW, Kühn H, Hennig B, Neish AS, Toborek M. IL4-induced oxidative stress upregulates VCAM-1 gene expression in human endothelial cells. J Mol Cell Cardiol. 2001;33(1):83-94. doi:10.1006/jmcc.2000.1278 
49. Doyle AG, Herbein G, Montaner LJ, et al. Interleukin-13 alters the activation state of murine macrophages in vitro: comparison with interleukin-4 and interferon-gamma. Eur J Immunol. 1994;24(6):1441-1445. doi:10.1002/ eji. 1830240630

50. White LJ, Castellano V, Mc Coy SC. Cytokine responses to resistance training in people with multiple sclerosis. J Sports Sci. 2006;24(8):911-914. doi:10.1080/02640410500357036

51. Rahimi R, Shoker Nejad H. Effects of $\beta$-Hydroxy- $\beta$ Methylbutyrate Supplementation on IL-4, IL-10 and TGF- $\beta 1$ during Resistance Exercise in Athletes. Preprints. 2017. doi:10.20944/preprints201705.0165.v1

52. Fu H, Yu P. [The effect of aerobic exercise on serum IL-4 and TNF-alpha of patients with allergic rhinitis]. Lin Chung Er Bi Yan Hou Tou Jing Wai Ke Za Zhi. 2013;27(23):13211323.

53. Boyd A, Yang CT, Estell K, et al. Feasibility of exercising adults with asthma: a randomized pilot study. Allergy Asthma Clin Immunol. 2012;8(1):13. doi:10.1186/17101492-8-13

54. Feingold KR, Grunfeld C. The acute phase response inhibits reverse cholesterol transport. J Lipid Res. 2010;51(4):682684. doi:10.1194/jlr.E005454

55. Hong KH, Cho ML, Min SY, et al. Effect of interleukin-4 on vascularendothelialgrowthfactorproduction in rheumatoid synovial fibroblasts. Clin Exp Immunol. 2007;147(3):573579. doi:10.1111/j.1365-2249.2006.03295.x

56. Tuomisto K, Jousilahti P, Sundvall J, Pajunen P, Salomaa V. C-reactive protein, interleukin- 6 and tumor necrosis factor alpha as predictors of incident coronary and cardiovascular events and total mortality. A population-based, prospective study. Thromb Haemost. 2006;95(3):511-518. doi:10.1160/ th05-08-0571 